\title{
Effect of Photobiomodulation on the Pain Reduction During and After Periodontal Surgery, Oral Surgery and Orthodontic Treatment: An Overview
}

ISSN: 2637-7764

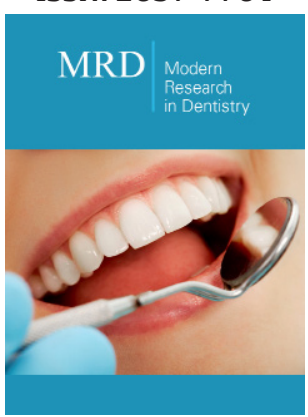

*Corresponding author: Muftah Agoob Alfergany, College of Dentistry and Oral Surgery, Zliten, Libya

Submission: 侮 May 06, 2019

Published: 海 May 21, 2019

Volume 4 - Issue 1

How to cite this article: Fuad A, Muftah A A. Effect of Photobiomodulation on the Pain Reduction During and After Periodontal Surgery, Oral Surgery and Orthodontic Treatment: An Overview. Mod Res Dent. 4(1). MRD.000579.2019.

DOI: 10.31031/MRD.2019.04.000579

Copyright@ Muftah Agoob Alfergany, This article is distributed under the terms of the Creative Commons Attribution 4.0 International License, which permits unrestricted use and redistribution provided that the original author and source are credited.

\author{
Fuad Alaijah* and Muftah Agoob Alfergany \\ College of Dentistry and Oral Surgery, Libya
}

\begin{abstract}
If pain occurs during or after the dental therapy, here it also requires more consultation and discussion to explain the cause of the pain and its possible reversibility. Moreover, in most cases, the patient will consider his physician rather worse. All this leads to the fact that in daily routine practice a pain sensation during or after the dental treatments should be avoided as much as possible. Photobiomodulation therapies were initially used as a shape of therapy more than 25 years ago. However, their activity in reducing postoperative pain after dental procedure remains suspicious, for this reason, we aimed to determine the overall treatment effects of photobiomodulation on postoperative pain relief through reviewing the literature. In the database PubMed, a literature search was carried out for the period from 2007 to May 2018. Only original works were evaluated and discussed. In addition, publications were included in this review that met the inclusion criteria and publications that do not fulfill the inclusion criteria were excluded. The literature has been searched for articles on the effect of photobiomodulation on the postoperative pain. The relevant contributions were made by the authors of this paper. Only 11 scientifically provable articles have been found, which also refer to the photobiomodulation on the postoperative pain. Photobiomodulation has been well established in the literature. Strategies to improve pain reduction during and after periodontal surgery, oral surgery and orthodontic treatment were also provided. Despite these efforts, further studies are needed, to develop a summary to facilitate researchers to do more scientific studies.
\end{abstract}

Keywords: Low-level laser; Photobiomodulation; Postoperative pain; Periodontal disease; Periodontal surgery; Oral surgery; Orthodontic treatment

\section{Introduction}

Periodontal surgery, oral surgery and orthodontic treatment can cause pain both during and after completion of the procedure. The management of pain is particularly critical in children and adolescents. Intraoperative dental pain can usually be removal by local anesthesia. Postoperative dental pain is largely ignored. Postoperative pain emerges from the activation of many passageways, transmission and mechanism process. One type of analgesic often fails to repress all these mechanisms, even when high dose is used [1]. although, treatment of pain, in general is a challenge, there is no reason to assume that pain treatment after surgery is not achievable. Several clinical studies investigated that photobiomodulation (PBM) effect to prevent pain or swelling after the third molars removal and surgical procedures as well as to reduce post-orthodontic pain, while some studies reported beneficial effects of PBM, others showed no [2] PBM it is a light therapy using low-level power lasers to improve wound repair and reduce postoperative pain, that utilizes non-ionizing forms of light origin, broadband light, in the visible and infrared spectrums [3]. There is a so-called optical window in tissue, known as the most depth of penetration in soft tissues through a laser beam, the wavelength is between 650 and 1200nm [4]. PBM can relieve pain and swelling after the surgical procedure, by making a positive effect on the immune response and stimulate lymphatic flow [5]. In addition to the ability of the PBM to stimulate blood circulation, which helps to increase the ability to absorb antibiotic in the body, the PBM has many features, including improvement and remodeling of collagen in the treatment of wounds [6]. 
PBM is an alternative treatment for postoperative pain, which is the main problem after periodontal surgical procedures. Compared to oral analgesics and non-steroidal anti-inflammatory drugs, PBM can be advantageous because the therapeutic window for its antiinflammatory action overlaps with its ability to improve tissue repair [7]. PBM effect on cells is related to various parameters, such as wavelength, pulse frequency, power density and time. According to the Arndt-Schulz law [8], "the light stimulus will be insufficient to trigger the target function if it is delivered below the recommended doses". If a dose higher than the indicated is given, it may inhibit activation of these functions. Study examining the analgesic effect of PBM have suggested that one should use a somewhat higher total dose to achieve an inhibitory effect [9], which indicates that weak stimuli will increase physiological procedure and strong stimuli will prevent physiological activity. The importance of this parameter should always be kept in mind when using PBM, if the clinician is not getting the anticipated response to laser treatment, they should reevaluate the dose being used to ensure it lies within the optimal range [5]. Moreover, treatments may need to be modified over time to ensure that the ideal effect of the laser dose is achieved (pain relief vs. wound healing). The aim of this review was to discuss the new literature concerning in vivo studies about the effect of PBM on the pain reduction during and after periodontal surgery, oral surgery and orthodontic treatment.

\section{Material and Methods}

Original research articles were used to investigate the effect of PBM on pain reduction during and after periodontal surgery, oral surgery and orthodontic treatment. PubMed database was the main source. Google Scholar has used a second search database for online resources where access was not approachable through MEDLINE, a literature search was carried out for the period from 2007 to May 2018. The research was confined to English language literature. The following keywords were used: Low-level laser
(LLL), photobiomodulation (PBM), postoperative pain, periodontal disease, periodontal surgery, oral surgery, orthodontic treatment'. The study selection process was performed by two blinded reviewers. The studies were considered eligible for inclusion in this systematic review if it met the following criteria,

(i) All human studies (in vivo studies)

(ii) Determine the following treatment parameters: power, power density, energy, energy density, the frequency of treatment, beam and dose (expressed in $\mathrm{J} / \mathrm{cm}^{2}$ ) and

(iii) A special condition during the treatment.

Excluded studies in the review were

(i) Studies that exclusively reported literature review

(ii) Histological studies and

(iii) Animal studies.

\section{Results}

The literature online portal PubMed has been searched. The search was carried out with the searching keywords: low-level laser (LLL), photobiomodulation (PBM), Postoperative pain, periodontal surgery, oral surgery and orthodontic treatment. A total of 1371 hits were scored. 1161 publication had to be ruled out because they were about wound healing and bone healing after PBM. Articles were seeming to be critical for inclusion in this review were 210 studies. Most of which were found multiple times. After removing duplicates and assessing the titles of the publications, 83 titles remained relevant to the inclusion criteria. These articles were read and evaluated by two independent examiners. Articles, which is not in English, case reports and "Reviews" were excluded as well as studies in which no clear distinction between pain and PBM were found. Eleven studies were completed by the analysis (Figure 1). The studies included in this review were listed in the Table 1.

Table 1: Laser irradiation conditions and results observed in vivo after effect of photobiomodulation (PBM) on the postoperative pain.

\begin{tabular}{|c|c|c|c|c|c|c|}
\hline Study & $\begin{array}{l}\text { Laser and Wave- } \\
\text { length (nm) }\end{array}$ & $\begin{array}{c}\text { Dose J/ } \\
\mathrm{cm}^{2}\end{array}$ & $\begin{array}{l}\text { Exposure } \\
\text { Time }\end{array}$ & Power & Place of Influence & Result \\
\hline $\begin{array}{l}\text { Ribeiro et al. } \\
\text { In vivo }\end{array}$ & $\begin{array}{l}\text { Diode } \\
780\end{array}$ & 35 & $20 \mathrm{~s}$ & $70 \mathrm{~mW}$ & $\begin{array}{l}\text { Subgingival scaling and root } \\
\text { planning }\end{array}$ & $\begin{array}{l}\text { Pain scale exhibited lower values } \\
\text { for the test side }\end{array}$ \\
\hline $\begin{array}{l}\text { Ramirez et al. } \\
\text { In vivo }\end{array}$ & $\begin{array}{l}\text { Diode } \\
810\end{array}$ & 4 & $32 \mathrm{~s}$ & $0.5 \mathrm{~W}$ & $\begin{array}{l}\text { The wound appeared after the } \\
\text { surgical removal of impacted } \\
\text { lower third molars }\end{array}$ & No effect \\
\hline $\begin{array}{l}\text { Sezer et al. } \\
\text { In vivo }\end{array}$ & $\begin{array}{c}\text { Nd:YAG } \\
1064 \\
\text { Diode } \\
808 \\
\text { Diode } \\
660\end{array}$ & $\begin{array}{l}8 \\
8 \\
8\end{array}$ & $\begin{array}{l}10 \mathrm{~s} \\
10 \mathrm{~s} \\
60 \mathrm{~s}\end{array}$ & $\begin{array}{l}0.25 \mathrm{~W} \\
0.25 \mathrm{~W} \\
0.04 \mathrm{~W}\end{array}$ & Acute pericoronitis & $\begin{array}{l}\text { At day } 7 \text { the pain level was sig- } \\
\text { nificantly reduced in all groups }\end{array}$ \\
\hline $\begin{array}{l}\text { Sanz-Moliner } \\
\text { et al. } \\
\text { In vivo }\end{array}$ & $\begin{array}{l}\text { Diode } \\
810\end{array}$ & 4 & $30 \mathrm{~s}$ & $0.1 \mathrm{~W}$ & Modified Widman flap & $\begin{array}{c}\text { Laser provided additional ben- } \\
\text { efits to MWF surgery in terms } \\
\text { of less edema and postoperative } \\
\text { pain. }\end{array}$ \\
\hline
\end{tabular}




\begin{tabular}{|c|c|c|c|c|c|c|}
\hline $\begin{array}{l}\text { Ferrante et al } \\
\quad \text { In vivo }\end{array}$ & $\begin{array}{l}\text { Diode } \\
980\end{array}$ & 54 & $60 s$ & $300 \mathrm{~mW}$ & $\begin{array}{l}\text { Pain, swelling, and trismus asso- } \\
\text { ciated with surgical removal of } \\
\text { impacted lower third molar }\end{array}$ & The intensity of pain was lower \\
\hline $\begin{array}{l}\text { Artes-Ribas } \\
\text { et al. } \\
\text { In vivo }\end{array}$ & $\begin{array}{l}\text { Diode } \\
830\end{array}$ & 5 & $20 s$ & $100 \mathrm{~W}$ & $\begin{array}{c}\text { Elastic separators are placed } \\
\text { between molars and premolars }\end{array}$ & Reduce pain \\
\hline $\begin{array}{l}\text { Doshi et al. } \\
\text { In vivo }\end{array}$ & $\begin{array}{c}\text { Diode } \\
660\end{array}$ & 4.5 & $3 \mathrm{~min}$. & $25 \mathrm{~mW}$ & Periodontal flap & Reduction of postoperative pain \\
\hline $\begin{array}{l}\text { Kazancioglu } \\
\text { et al. } \\
\text { In vivo }\end{array}$ & $\begin{array}{l}\text { Diode } \\
808\end{array}$ & 4 & $120 \mathrm{~s}$ & $0.1 \mathrm{~W}$ & Pain after third molar surgery & Positive effect \\
\hline $\begin{array}{l}\text { Sobouti et al. } \\
\text { In vivo }\end{array}$ & $\begin{array}{c}\text { Diode } \\
940\end{array}$ & $\begin{array}{l}\text { No } \\
\text { info }\end{array}$ & $30 \mathrm{~s}$ & $0.9 \mathrm{~W}$ & Cosmetic smile lift gingivectomy & Reduce pain \\
\hline $\begin{array}{l}\text { Qamruddin } \\
\text { et al. } \\
\text { In vivo }\end{array}$ & $\begin{array}{l}\text { Diode } \\
940\end{array}$ & 4 & $20 s$ & $200 \mathrm{~W}$ & $\begin{array}{l}\text { Spontaneous and chewing pain } \\
\text { after the placement of elasto- } \\
\text { meric separators }\end{array}$ & Reduce pain \\
\hline $\begin{array}{l}\text { Ravi M et al. } \\
\quad \text { In vivo }\end{array}$ & $\begin{array}{c}\text { Diode } \\
980\end{array}$ & 4 & $90 \mathrm{~min}$ & $0.1 \mathrm{~W}$ & Kirkland flap (KF) surgery & $\begin{array}{l}\text { Effect on the immediate postop- } \\
\text { erative pain and thus reducing } \\
\text { the need for analgesic consump- } \\
\text { tion }\end{array}$ \\
\hline
\end{tabular}

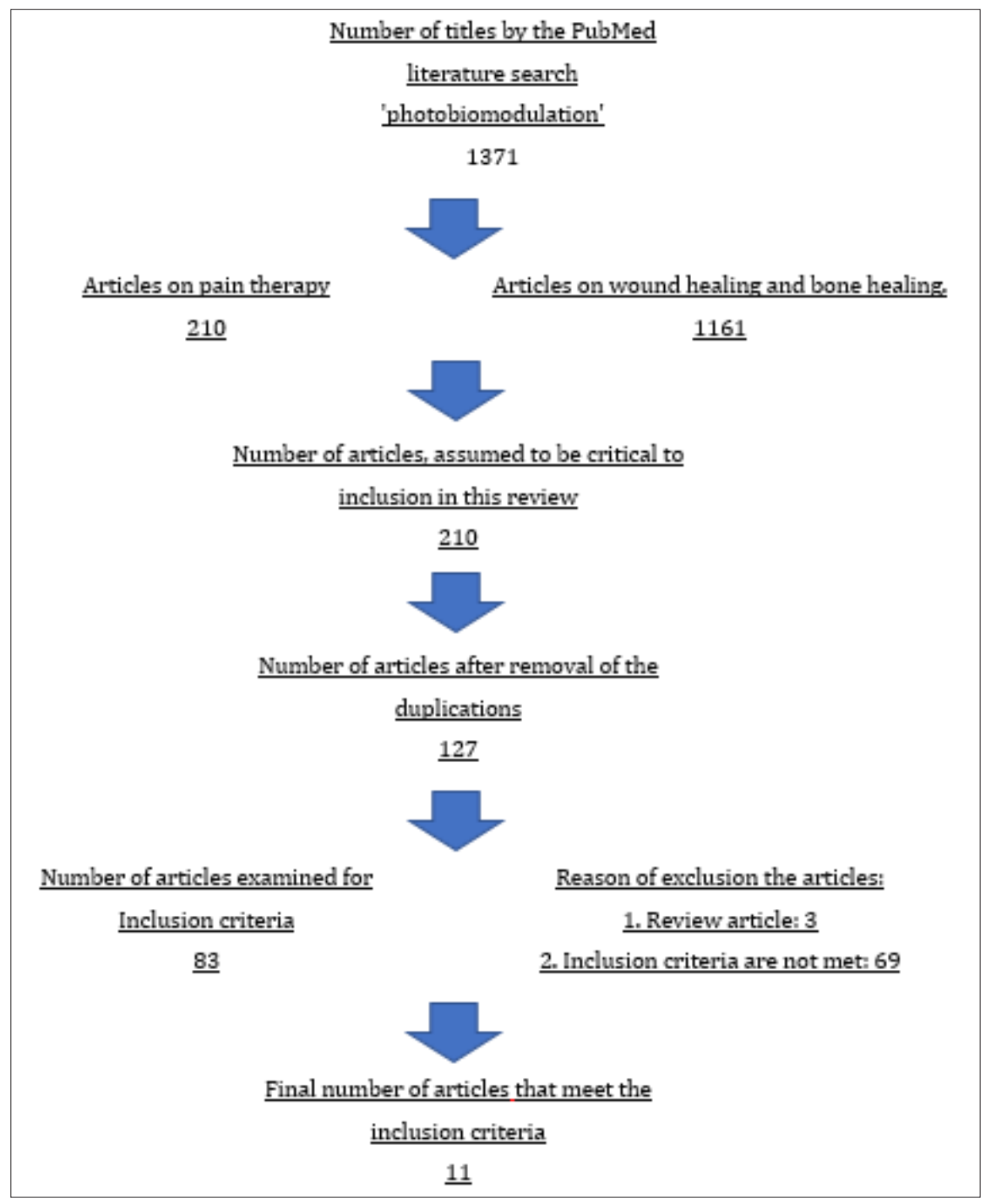

Figure 1: The literature search strategy. 


\section{Discussion}

photobiomodulation is just one of many modern tools which we can use in our everyday dental work. When used properly and with the appropriate expectations, PBM can be an advantageous tool. Like any treatment, the patient's experience and therapy outcome may vary from one to another. It has been observed that some people do not respond to treatment and this occurs when the device is used incorrectly, that is, the device is set to weak standards or that the treatment simply not suitable for the patient (28). Moreover, laser use in PBM depends highly on the skill and experience of the operator, especially that understanding the terms and parameters of the different laser devices can be difficult for the untrained dentist, as calculating all these powers and dosages may be a daunting task. As with any treatment or therapy that a dentist may provide, informed consent must be obtained through discussion with the patient about reasonably possible risks and benefits of the procedure as well as what might happen without the procedure. Further in vivo investigations are necessary to determine the optimal laser parameters and irradiation protocols to improve the pain reduction during and after periodontal surgery, oral surgery and orthodontic treatment. Patient education is necessary to be able to apply the laser treatment to improve the pain reduction during and after periodontal surgery, oral surgery and orthodontic treatment in the clinic. As a result, a dentist may expect a cost benefit return when more patients are familiar with the advantages of the laser and favour its value.

\section{Effect of PBM on pain in periodontal diseases}

Since the periodontal disease is an inflammatory disease of tooth-supporting tissues caused by specific microorganisms, which lead to progressive destruction of the periodontal membrane and alveolar bone, with the formation of periodontal pockets and gingival recession [10]. The main purpose of the treatment of periodontitis is to manage the infection and to promote the healing of the periodontal tissue. Scaling and root planing have been confirmed by many studies as an effective treatment for periodontitis. The conventional periodontal treatment can be enhanced by using Erbium lasers. On the antibacterial effect of using erbium lasers as an adjunctive to the SRP, Alfergany MA, et al. have done a review study and they have concluded that using erbium lasers resulted in a significant reduction in the level of the periodontal microorganisms, which is the key to success the treatment of periodontal disease [11]. It is well known that this treatment is unpleasant for the patients even in many cases it may be painful which necessitates using the anesthesia during the treatment. Recently incorporating the laser technology in treating the periodontal disease, specially the low-level laser, because of their effectiveness in improving the healing process, lowering pain after surgery and treatment of paraesthesia, sensitive teeth, and many other painful condition, in addition to promoting a faster dentin formation, and they are mostly recommended in periodontology to reduce the patient's complaints and discomfort caused by hypersensitivity or pain after surgical procedures [12]. Data from in vivo study (Doshi et al.) indicated that $660 \mathrm{~nm}$ diode laser $(25 \mathrm{~mW}$, continues mode CW, 4.5J, $3 \mathrm{~min}$ exposure time, $3 \mathrm{~cm}$ distance to the marginal gingiva, in a sweeping motion, 3 consecutive days) has both desensitizing and analgesic action 7 days following periodontal flap surgery [13].

In another study, it was demonstrated that the pain scale exhibited lower values for the test side with laser energy applied at a wavelength of $780 \mathrm{~nm}\left(35 \mathrm{~J} / \mathrm{cm}^{2}, 20 \mathrm{~s}\right.$ per site) [14]. (LLLT) has been suggested as an alternative method for postoperative pain control compared to oral analgesics and non-steroidal antiinflammatory drugs, (LLLT) can be advantageous because the therapeutic window for anti-inflammatory action overlaps with its ability to improve tissue repair [15]. The study pointed out that obtained reduction of postoperative pain by applying the $660 \mathrm{~nm}$, $808 \mathrm{~nm}$ wavelength diode laser and the $1064 \mathrm{~nm} \mathrm{Nd}$ : YAG laser with $8 \mathrm{~J} / \mathrm{cm}^{2}$ energy density at day 7 [16]. Other authors have these therapeutic effects despite applying this same amount of energy $4 \mathrm{~J} /$ $\mathrm{cm}^{2}$ and same wavelength $810 \mathrm{~nm}[17,18]$.

\section{Effect of PBM on pain in oral surgery}

The primarily effective principle of low-level laser therapy (LLLT) is the so-called laser biostimulation. The exact mechanism of how it works is very complex and beyond the scope of this review. Basically, it is based on stimulating the mitochondria by absorption of different radiation. These absorptions, which increases the supply of ATP in the cell. Furthermore, increased vasodilation of the vessels, increased macrophage activity, yielded an anti-inflammatory effect and much more healing activity was observed [19]. Better coagulation provides a dry and isolated environment, which allows a better control and less infection rate. This might be associated with reduced post-surgical pain $[20,21]$. In one experiment, it was reported that the diode laser $940 \mathrm{~nm}$ with $4 \mathrm{~J} / \mathrm{cm}^{2}$ energy density assisted surgery by having an astounding effect on pain in gingivectomy surgery which reduce post-surgical pain and bleeding [22]. Moreover, another author has demonstrated that diode laser $980 \mathrm{~nm}$ with the same parameter, is useful for the reduction of postoperative discomfort after, third molar surgery [23]. Another study used the wavelength of 810 $\mathrm{nm}$ and higher power with a shorter time of laser application to approach an energy density of $4 \mathrm{~J} / \mathrm{cm}^{2}$, but this study didn't show beneficial effects in reducing pain [24]. In fact, pain intensity and degree of inflammation can vary among patients, which might have influenced the results. A study evaluated the efficacy of the ozone and a gallium-aluminum-arsenide (GaAlAs) diode laser $(0.1 \mathrm{~W}$, $120 \mathrm{~s}, 4 \mathrm{~J} / \mathrm{cm}^{2}$ ) application in the management of pain, swelling and trismus after third-molar surgery. The result showed an $808 \mathrm{~nm}$ diode laser has a positive effect [18]

\section{Effect of PBM on pain in orthodontics}

Pain that can occur during orthodontic treatments is uncomfortable for patients. Sometimes analgesic should be given to the patients during the orthodontic treatment to reduce pain, but these drugs according to the literature have been shown to reduce the movement velocity of the teeth [25]. Thus, the inhibition of prostaglandin synthesis, the intermediary in the onset of pain, 
has an influence on bone resorption [25]. In addition, side effects or allergies can occur. However, studies analyzed the efficacy of the low-level laser therapy (LLLT) as a potential alternative to drug in the pain management during the orthodontic therapy. An in vivo study was able to evaluate pain-relieving effects with an AIGaAs diode laser. They showed that a better orthodontic movement of the teeth can be achieved by using a diode laser of $830 \mathrm{~nm}, 100 \mathrm{~mW}$, beam diameter of $7 \mathrm{~mm}, 250 \mathrm{~mW} / \mathrm{cm}^{2}$ applied for $20 \mathrm{~s}$ per point $(5 \mathrm{~J} /$ $\mathrm{cm}^{2}$ ). At the same time, it can reduce pain and discomfort [26]. Also, in another study was seen that, the effect of a single dose of lowlevel diode laser $(940 \mathrm{~nm}$, power set at $200 \mathrm{~mW}$, the energy dose was $4 \mathrm{~J} / \mathrm{cm}^{2}$ ) therapy on spontaneous and chewing pain after locating of orthodontic elastomeric separators, the low-level laser was utilized for 20 second on 3 points buccally mesial, distal and middle of the root of the permanent first molar. The outcome showed that diode laser with a $940 \mathrm{~nm}$ wavelength can reduce pain confederates with the placement of separators in orthodontics [27]. All studies show that (LLLT) contributes to pain relief in orthodontic treatments also as an essential factor affecting the efficiency of (LLLT), laser type, wavelength and intensity of treatment was clarified. Although a reduction in pain was noted, further research will be needed before (LLLT) can establish itself as an alternative method.

\section{Conclusion}

The clinical implementation for each of the diode and $\mathrm{Nd}$ : YAG lasers as PBM therapy improves control of the pain during and after periodontal surgery, oral surgery and orthodontic treatment. However, considering the high number of positive reports currently available in the literature, PBM seems to be a safe and effective treatment option for the pain during and after periodontal surgery, oral surgery and orthodontic treatment. But the results of this review considered that the reviewed studies are not sufficient to confirm the effectiveness of (PBM), but further new in vivo investigations are necessary to determine the optimal laser parameters and irradiation protocols to improve the pain reduction during and after periodontal surgery, oral surgery and orthodontic treatment.

\section{References}

1. Pandya NM, Dhalla NS, Santini DD (2006) Angiogenesis-a new target for future therapy. Vascular Pharmacol 44(5): 265-274.

2. Weis SM, Cheresh DA (2005) Pathophysiological consequences of VEGFinduced vascular permeability. Nature 437(7058): 497-504.

3. Ferrara N, Gerber HP, Lecouter J (2003) The biology of VEGF and its receptors. Nat Med 9(6): 669-676.

4. Thomas M, Augustin HG (2009) The role of the angiopoietins in vascular morphogenesis. Angiogenesis 12(2): 125-137.

5. Clavel G, Bessis N, Lemeiter D, Fardellone P, Mejjad O, et al. (2007) Angiogenesis markers (VEGF, soluble receptor of VEGF and angiopoietin-1) in very early arthritis and their association with inflammation and joint destruction. Clin Immunol 124(2): 158-164.

6. Fiedler U, Augustin HG (2006) Angiopoietins: a link between angiogenesis and inflammation. Trends Immunol 27(12): 552-558.
7. Fagiani E, Christofori G (2013) Angiopoietins in angiogenesis. Cancer Lett 328(1): 18-26.

8. Hanahan D (1997) Signaling vascular morphogenesis and maintenance. Science 277(5322): 48-50.

9. Tipoe GL, Jin Y, White FH (1996) The relationship between vascularity and cell proliferation in human normal and pathological lesions of the oral cheek epithelium. Eur J Cancer B Oral Oncol 32B(1): 24-31.

10. Gandolfo M, Keszler A, Lanfranchi H, Itoiz ME (2011) Increased subepithelial vascularization and VEGF expression reveal potentially malignant changes in human oral mucosa lesions. Oral Surg Oral Med Oral Pathol Oral Radiol Endod 111(4): 486-493.

11. Xue JL, Fan MW, Wang SZ, Chen XM, Li Y, et al. (2005) A clinical study of 674 patients with oral lichen planus in China. J Oral Pathol Med 34(8): 467-472.

12. Warnakulasuriya S, Johnson NW, Van der Wall I (2007) Nomenclature and classification of potentially malignant disorders of the oral mucosa. J Oral Pathol Med 36(10): 575-580.

13. Tao X, Huang Y, Li R, Qing R, Ma L, Rhodus Nl et al. (2007) Assessment of local angiogenesis and vascular endotelial growth factor in the patients with atrophic-erosive and reticular oral lichen planus. Oral Surg Oral Med Oral Pathol Oral Radiol Endod 103(5): 661-669.

14. Mardani M, Ghabanchi J, Fattahi MJ, Tadbir AA (2012) Serum level of vascular endothelial growth factor in patients with different clinical subtypes of oral lichen planus. Iran J Med Sci 37(4): 233-237.

15. Hazzaa HHA, El Wakeel NM, Attia EAS, Hager EAA (2016) ALKI expression in oral lichen planus: a possible relation to microvessel density. J Oral Pathol Med 45(5): 373-380.

16. Mittal N, Shankari GM, Palaskar S (2012) Role of angiogenesis in the pathogenesis of oral lichen planus. J Oral Maxillofac Pathol 16(1): 45-48.

17. Scardina GA, Picone V, Cacioppo A, Messina P (2007) Study of microcirculation in oral lichen planus by video-capillaroscopy. Oral Surg Oral Med Oral Pathol Oral Radiol Endod 103(4): e30-4.

18. Pindborg, JJ, Reichart PA, Smith CJ, Van der Wall I (1997) World Health Organization International. Histological Classification of Tumours. Histological Typing of Cancer and Precancer of the Oral Mucosa. $\left(2^{\text {nd }}\right.$ edn), Springer, Berlin, Germany.

19. Lee JJ, Kuo MY, Cheng SJ, Chiang CP, Jeng JH, et al. (2005) Higher expressions of p53 and proliferating cell nuclear antigen (PCNA) in atrophic oral lichen planus and patients with areca quid chewing. Oral Surg Oral Med Oral Pathol Oral Radiol Endod 99(4): 471-478.

20. Silverman S (2000) Oral lichen planus: a potentially premalignant lesion. J Oral Maxillofac Surg 58(11): 1286-1288.

21. Shen ZY, Liu W, Zhu LK, Feng JQ, Tang GY, et al. (2012) A retrospective clinicopathological study on oral lichen planus and malignant transformation: analysis of 518 cases. Med Oral Patol Oral Cir Bucal 17(6): e943-e947.

22. Chien CY, Su CY, Chuang HC, Fang FM, Huang HY, et al. (2008) Angiopoietin-1 e-2 expression in recurretn squamous cell carcinoma of the oral cavity. J Surg Oncol 97: 273-277.

23. Pereira JS, Monteiro BV, Nonaka CF, Silveira ÉJ, Miguel MC (2012) FoxP3(+) T regulatory cells in oral lichen planus and its correlation with the distinct clinical appearance of the lesions. Int J Exp Pathol 93(4): 287-294.

24. Taylor PC (2005) Serum vascular markers and vascular imaging in assessment of rheumatoid arthritis disease activity and response to therapy. Rheumatology (Oxford) 44(6): 721-728. 
25. Al Hassiny A, Friedlander LT, Parachuru VPB, Seo B, Hussaini HM, et al (2018) Upregulation of angiogenesis in oral lichen planus. J Oral Pathol Med 47(2): 173-178.

26. Sousa FA, Paradella TC, Carvalho YR, Rosa LE (2009) Immunohistochemical expression of PCNA, p53, bax and bcl-2 in oral lichen planus and epithelial dysplasia. J Oral Sci 51(1): 117-121.
27. de Sousa FA, Paradella TC, Carvalho YR, Rosa LE (2009) Comparative analysis of cell proliferation ratio in oral lichen planus, epithelial dysplasia and oral squamous cell carcinoma. Med Oral Patol Oral Circ Bucal 14(11): e563-e567.

For possible submissions Click below: 